\title{
E no asilo, tem teatro? Relatos de uma experiência com o teatro na comunidade
}

Vanderlei Antonio Bachega Junior ${ }^{1}$

Gabriela Pereira Fregoneis²

Submetido em:15/04/2020

Aprovado em: 26/05/2020

DOI: $10.5965 / 2358092521232020224$

1 Mestrando em Teatro na Universidade do Estado de Santa Catarina (UDESC). Professor, ator e iluminador. E-mail: vandbjunior@gmail.com

2 Doutora em Artes da Cena pela Universidade Estadual de Campinas (Unicamp). Professora Temporária no Curso de Artes Cênicas da Universidade Estadual de Maringá (UEM).

E-mail: gabiangelus@hotmail.com 


\section{RESUMO}

O relato em questão se ateve a articular a temática do Teatro na Comunidade, comentando uma experiência de ensino do teatro com idosos residentes de uma instituição de longa permanência. A prática de ensino permitiu observar os conceitos sobre o Teatro na Comunidade e refletir sobre as possíveis formas de manifestação do fazer teatral em um asilo. A experiência se refere à produção e execução de um projeto de ensino desenvolvido por graduandos em Teatro, no contexto de uma disciplina de estágio na comunidade.

Palavras-chave: idosos, ensino, teatro na comunidade.

\section{ABSTRACT}

This article attempted to articulate the theme Community Theater, arguing about an experience of theater teaching with elderly residents of a long-term institution. The theatre teaching allowed us to observe the concepts about Community Theater and reflect about the possible manifestations of theater in a long-term institution. The experience refers to the production and execution of a teaching project developed by graduates in Theater, in the context of an internship discipline with communities.

Keywords: seniors, education, community theater.

Neste texto relatamos uma prática de ensino do teatro com idosos, a fim de observar as possíveis formas de manifestação do teatro em asilos. Para isso relacionamos as experiências desenvolvidas com estudos sobre Teatro na Comunidade, impulsionados por Márcia Pompeo Nogueira, estudos sobre a prática teatral com idosos e a experiência em questão.

Entendemos por Teatro na Comunidade, as práticas liga- 
das ao teatro "Sempre que o ponto de partida [de uma prática teatral] for a natureza de seu público e sua comunidade. Que a estética de suas performances for talhada pela cultura da comunidade de sua audiência". (KERSHAW, 1992, p. 5 apud NOGUEIRA, 2009, p. 173). Não há uma única visão e definição sobre Teatro na Comunidade, o assunto é compreendido por diferentes estudiosos por perspectivas distintas. Essa apresentada por Nogueira (2009), se apresenta como a mais condizente ao contexto que relataremos a seguir, uma vez que permite compreender diferentes formas de ver, fazer e estar no teatro, seja através da formação de grupos teatrais ou da participação de atividades eminentemente pedagógicas.

Quanto às possibilidades de trabalho com o teatro no contexto da comunidade, Nogueira (2009), expõe uma diversificação de modalidades: o teatro para comunidades, que se refere ao teatro produzido por artistas apresentado a comunidades; 0 teatro com comunidades, que envolve o contato e pesquisa com a cultura de uma comunidade, para a produção de uma prática teatral feita por artistas; o teatro por comunidades, que inclui pessoas da comunidade como agentes nos processos da prática teatral. Ainda que as modalidades apresentadas pela autora se refiram ao teatro enquanto apresentação artística e elaboração de encenações, visualizamos como uma possível vertente do fazer teatral, as atividades teatrais de caráter eminentemente pedagógico, direcionadas as especificidades de determinada comunidade.

A partir disso, narramos aqui a presença do teatro, como atividade pedagógica, em uma comunidade de idosos que reside em uma instituição de longa permanência: o Asilo São Vicente de Paulo (ASVP) ${ }^{3}$. O teatro com idosos ganha espaço na sociedade contemporânea pois, 
[...] se apresenta como uma atividade saudável que amplia a potencialidade da qualidade de vida, restaura o fazer da cidadania e alimenta o campo emocional com atividades físicas, ações emotivas, desenvolvimento da personalidade e exercício da memória. (RIBEIRO, 2009, p. 133).

Nos últimos anos podemos observar o fortalecimento do campo de estudos acadêmicos relacionados aos idosos, sendo um deles as artes cênicas. Além das práticas profissionais que visam bem-estar físico e emocional, destacamos a ascensão de atividades artísticas voltadas a este grupo. No teatro podemos ressaltar o surgimento de grupos de teatro, profissionais e amadores, formados prioritariamente por atores e atrizes idosos e a oferta de cursos e oficinas dedicadas especificamente para o público.

Assim como outras áreas que se dedicam ao estudo da população idosa e ao envelhecimento, o teatro com pessoas idosas pode receber diferente nomenclaturas, como teatro na terceira idade ou na melhor idade. Entretanto, essas nomenclaturas podem desconsiderar o envelhecimento como uma "experiência heterogênea, vivida como uma experiência individual". (SCHNEIDER; IRIGARAY, 2008, p. 586), já que, se comparada com décadas anteriores, é possível visualizar um progresso na meIhoria da qualidade e estimativa de vida da população idosa, nos permitindo conviver com diferentes exemplos de idosos de uma idade.

Schneider e Irigaray (2008), discutindo as nomenclaturas utilizadas para o envelhecimento, alertam que os termos terceira idade e melhor idade podem sugerir visões turvas sobre o envelhecimento. O termo terceira idade é resquício de um processo relacionado a aposentadoria de idosos e, normalmente, categoriza como idosos aqueles que já passaram dos sessenta anos de idade. Contudo, a idade não deve ser o fator que indica o envelhecimento. O termo melhor idade tem histórico comercial, muito utilizado para vender um aspecto romantizado do envelhecer e atividades voltadas a ele. Dessa forma, para não considerar o envelhecimento como um processo negativo, 
e sim, inerente a vida humana, utilizaremos o termo teatro com idosos como forma de referência ao público que reside no asilo.

Observando as plataformas de pesquisa acadêmica, notamos que grande parte dos relatos sobre práticas teatrais com idosos estão ligados a formação de grupos de teatro, a produção e montagem de encenações destes grupos. Esta constatação nos levou a refletir sobre os modos de se fazer teatro com idosos. É necessário que o fazer teatral desencadeie uma encenação, um produto final? Quais os possíveis caminhos formativos dentro das práticas teatrais existentes? Quais são as reais necessidades deste público específico? Há espaço (além do espaço físico) para se fazer teatro em um asilo? Não nos atemos a responder essas questões neste relato, mas desejamos por meio do compartilhamento de experiências refletir sobre o fazer teatral na comunidade.

A prática de ensino em questão aconteceu no contexto das disciplinas "Estágio na Comunidade I e II" e "Ensino do Teatro na Comunidade I e II" do curso de graduação em Artes Cênicas da Universidade Estadual de Maringá, no ano de 2018. As disciplinas referentes ao estágio obrigatório contaram com a parceria de instituições públicas para a realização de projetos e práticas docentes em teatro, realizadas pelos graduandos de licenciatura, com orientação dos respectivos professores e supervisão de profissionais de cada instituição.

O ASVP é instituição de longa permanência que presta cuidados a idosos em condição de risco pessoal e social, que não podem permanecer sobre os cuidados da família, ou ainda, não possuem família. Ele presta assistência a cerca de cem idosos em diferentes condições físicas e mentais, tendo um grupo bastante heterogêneo e com rotatividade. A instituição oferece atividades que se somam a residência dos idosos no local, como ações saúde (dentre elas a fisioterapia e a terapia ocupacional) e recreação por meio de eventos e apresentações artísticas. A prática de ensino do teatro se deu na atividade da Terapia Ocupacional $(\mathrm{T} . \mathrm{O})^{4}$, o que não significa que o teatro foi associado às

4 A Terapia Ocupacional é uma área da saúde que "promove prevenção, tratamento, rea- 
atividades terapêuticas que já eram desenvolvidas ou se intencionou como arte terapia, mas que o momento foi cedido para a realização de práticas do teatro.

A primeira instância, os graduandos passaram por um período de observação do ambiente, da comunidade e do trabalho do profissional responsável (terapeuta ocupacional), auxiliando- o na condução de suas atividades. Após o período de observação o grupo de graduandos que atuou no asilo em questão, elaborou um projeto de ensino que posteriormente foi conduzido naquela comunidade. O projeto desenvolvido, "Memórias de nós mesmos: lembrar é refazer"s, almejava por meio do teatro, trabalhar com as subjetividades apresentadas pelos idosos em seus relatos pessoais observados durante as atividades da T.O.

Para a elaboração do projeto e planejamento das práticas, os graduandos adotaram como fatores indicativos da ação docente alguns fatos recorrentes observados, dentre eles a participação e rotatividade do grupo. A T.O não era considerada uma atividade obrigatória a todos os idosos da instituição, assim, o grupo já era reduzido a aproximadamente vinte idosos (homens e mulheres), entretanto, alguns escolhiam quando participariam, levando como critério a atividade a ser desenvolvida em cada encontro, evidenciando uma relação de interesse. Esses dois pontos (rotatividade e interesse), levaram a compreender que seria dificultoso elaborar atividades com continuidade e que estimulassem a formação de um grande grupo, pois sempre haveria troca de participantes. Por isso, os graduandos escoIheram elaborar uma sequência de encontros com atividades de duração única, que pudessem ser iniciadas e finalizadas naquele período.

\footnotetext{
bilitação de indivíduos portadores de alterações genéticas, afetivas, perceptivas e psicomotoras, decorrentes ou não de distúrbios genéticos, traumáticos ou de doenças adquiridas por meio da utilização da atividade humana como base de desenvolvimento de projetos terapêuticos específicos. (CREFITO-9, 2019)".

5 Este projeto foi desenvolvido durante disciplina de Ensino de Teatro na Comunidade I, do curso de Artes Cênicas da Universidade Estadual de Maringá, sob orientação da Prof. . Dra. Gabriela Fregoneis. A elaboração do projeto teve como fundamentação as observações realizadas pelos discentes, realizados na disciplina de Estágio na Comunidade I.
} 
O grupo de idosos que participou das práticas apresentava uma grande heterogeneidade quanto às questões físicas e mentais. Participavam idosos com boa condição de saúde e mobilidade, mas também com dificuldade de locomoção, sendo alguns deles cadeirantes, utilizadores de bengalas e andadores, idosos com coordenação motora-fina afetada e também portadores de doenças degenerativas que apresentavam dificuldades comunicativas e mentais. De tal forma, os graduandos adotaram, desde o momento de elaboração das atividades, uma postura que visava acessibilidade a todos, seja pela adaptação de jogos e exercícios, ou pelo acompanhamento individual dos idosos mais debilitados durante as atividades.

A temática do projeto desenvolvido, a memória, emerge como uma sugestão do grupo de estagiários a partir do período de observação, já que havia uma grande reincidência de momentos em que os idosos narravam suas próprias histórias. A partir disso, elencamos os assuntos mais recorrentes: histórias de amor (namorados e relacionamentos); esportes e futebol; histórias de infância; trajetória escolar; histórias sobre conhecidos (familiares, amigos e vizinhos); o rádio e a televisão; as suas primeiras vezes e as suas relações com a música (memórias, ouvir, cantar e tocar instrumentos). Assim, foram elaborados nove encontros, totalizando dezoito horas de duração, que mesclavam jogos tradicionais, teatrais e dramáticos e outras atividades de acordo com cada temática.

As narrativas pessoais e os temas de cada encontro operaram como disparadores da imaginação, que foi instigada pela escolha do trabalho com materialidades (objetos), como cartas, fotografias, vídeos, músicas, jogos de mesa e objetos cotidianos aliados às práticas teatrais. Como comenta Carneiro (2013), o objeto material e imagético pode atuar como um provocador da imaginação, ao gerar uma reação em cadeia, devido aos estímulos, permitindo que a própria mente entre em atividade. A imaginação aguçada pelas imagens, permite estabelecer uma experiência "bastante rica para o processo de desenvolvimento das questões relativas ao movimento, o espaço e outras percepções ligadas a aspectos criativos da interpretação". (CARNEIRO, 
2013, p. 29).

Nesse processo, alguns encontros se destacaram devido às devolutivas dos idosos, como o encontro sobre as histórias de amor, que nos surgiu a partir dos relatos pessoais sobre paqueras, grandes paixões, namoros e casamentos. Os relatos nos levaram a relacionar histórias de amor com possíveis dramaturgias teatrais que fizessem parte do repertório da maioria dos idosos. Optamos por elaborar um encontro sobre Romeu e Julieta de William Shakespeare, por supor que, devido à popularidade, haveria a possibilidade de já conhecerem a história.

Metodologicamente, nos inspiramos no estímulo composto proposto por Jonh Sommers e em alguns procedimentos do ensino do Drama $^{6}$ e criamos um compilado de cartas que compuseram uma caça a cartas de amor.

A noção de estímulo composto, sistematizada por John Sommers (1999), permite imaginar personagens e histórias no Drama, com base na combinação de objetos e documentos que sugerem conteúdos e espaços ficcionais nos quais estes estejam envolvidos. (MENDONÇA, 2013, p. 128)

Os graduandos transcreveram a narrativa da peça para o formato de cartas, estabelecendo duas versões: uma narrada pela voz de Julieta e a outra pela voz de Romeu. Espalharam estas cartas pelo asilo, dividiram os idosos em dois grupos de caçadores e não contaram a eles que história estava contida nessas cartas, apenas que deveriam desvendar a narrativa ao fim da atividade. Os grupos saíram à caça de um ponto central onde havia uma primeira carta e uma pista que revelava onde se encontraria próxima e assim por diante. Ao encontrar cada envelope, os idosos alfabetizados eram convidados a ler as cartas em voz alta para o grupo ou os licenciandos realizavam a leitura. Alguns idosos, inclusive, interpretavam a leitura de forma dra-

6 Vale ressaltar que o Drama e o estímulo composto nos serviram nessa experiência apenas como disparadores metodológicos e a prática desenvolvida não se assemelhou ou se intencionou a criação de um processo de criação de uma narrativa, como a própria metodologia intui. 
mática. Ao fim da caça, os grupos compartilharam suas versões da mesma história. Depois de alertados que a história era conhecida, tentaram adivinhar de que história se tratava. Apenas uma idosa identificou, mas logo depois, todos perceberam que já conheciam a famosa dramaturgia.

Após uma breve e simples explicação sobre a peça e o autor, os idosos relataram suas experiências com o teatro. A maioria já havia assistido peças ou frequentado teatros quando mais jovens, principalmente espetáculos circenses, também relataram que algumas vezes saíram a passeio com a equipe do asilo para ir ao teatro e ao cinema e que grupos amadores e palhaços já haviam se apresentado no local.

Posteriormente, no mesmo encontro, contaram sobre suas histórias de amor. Enquanto contavam, os idosos usavam de alguns recursos de interpretação para narrar suas histórias pessoais, como a gestualidade, modificações corporais e modulações vocais, evidenciando aos estagiários uma forma de explorar a linguagem do teatro. Nos encontros seguintes, essas características eram estimuladas com perguntas: como essa pessoa da sua história falava? Como ela andava?

A elaboração e realização do projeto de ensino como um todo não tinha como objetivo ensinar técnicas de interpretação teatral, improvisação ou qualquer outra técnica relacionada ao teatro. A proposição tinha como intenção proporcionar vivências artísticas capazes de estimular os idosos criativamente, por meio da narração de suas histórias pessoais, incitadas pelas atividades teatrais.

Nesta experiência de ensino, o teatro não se fez presente na comunidade enquanto encenação ou enquanto prática de montagem, ou ainda processo de preparação de atores. O teatro com idosos se deu no encontro de sujeitos distintos que moravam no mesmo local, mas não apresentavam uma assídua convivência. $\mathrm{O}$ teatro se manifestou com troca experiências sobre a vida, na observação do eu e do outro, no arriscar-se a se posicionar, no espaço confortável estabelecido para se expressar, no abandono da vergonha ao se manifestar, no exercício da paciência em respeitar as limitações do outro, no respeito à 
convivência e na escuta de si e do outro.

[...] a pedagogia do como um ato criativo é uma realização da necessidade de criar uma cultura teatral, uma dimensão do teatro cujos espetáculos somente satisfazem parcialmente, e que a imaginação traduz em tensão vital. (BARBA; SAVARESE, 1995, p. 28 apud TELLES, 2013, p. 19).

Além da afetar aqueles que participaram diretamente das atividades, a presença do teatro instigou curiosidade e estranhamento nos outros idosos residentes da comunidade. Durante os encontros, seja dentro da sala de atividades ou no pátio, olhares atentos e curiosos cercavam o ambiente, indicando que o teatro pode em alguns momentos, modificar a dinâmica do espaço.

O teatro com idosos se apresentou como aliado na melhoria da qualidade de vida e convivência em grupo da comunidade, seja como prática pedagógica ou como forma de entretenimento. Neste asilo, estabelecendo uma relação com os conceitos de Nogueira (2009), produziu-se um teatro para a comunidade, oferecendo aos idosos, independentemente da condição física e mental, a experiência do espectador, do apreciador, sendo ele refúgio do cotidiano atravessado por circunstâncias. No asilo também pode haver teatro com a comunidade seja como prática de encenação, ou como uma experiência pedagógica.

Esta experiência de ensino do teatro na comunidade nos proporcionou compreender que, mesmo que o teatro não se manifeste pela produção de um produto artístico final, a pedagogia do teatro proporciona a possibilidade de abraçar as situações e suas circunstâncias, e por meio da observação crítica e reflexiva, estabelecer caminhos e estratégias para suscitar as principais características da linguagem teatral evocadas nas experiências artísticas, considerando as individualidades de cada grupo ou comunidade, podendo proporcionar mudanças no aspecto social. 


\section{REFERÊNCIAS}

CARNEIRO, Ana. A Pedra Lançada no Pântano: imagens e aquisição de conceitos no ensino do teatro: imagens e aquisição de conceitos no ensino do teatro. In: TELLES, Narciso (org.). Pedagogia do Teatro: práticas contemporâneas na sala de aula. Práticas contemporâneas na sala de aula. Campinas: Papirus, 2013. p. 23-74. CREFITO-9. Conselho Regional de Fisioterapia e Terapia Ocupacional da $9^{a}$ Região. O que é Terapia Ocupacional? Disponível em: <https://www.crefito9.org.br/ terapia-ocupacional/o-que-e-terapia-ocupacional/164> . Acesso em: 07 de abril de 2020.

MENDONÇA, Celida Salume. Montagem em sala de aula: os princípios norteadores de um processo. In: TELLES, Narciso (org.). Pedagogia do Teatro: práticas contemporâneas na sala de aula. Práticas contemporâneas na sala de aula. Campinas: Papirus, 2013. p. 123-150.

NOGUEIRA, Marcia Pompeo. Teatro e Comunidade. In: FLORENTINO, Adilson; TELLES, Narciso (org.). Cartografias do Teatro. Uberlândia: Edufu, 2009. p. 173-183.

RIBEIRO, José Luiz. O Teatro na Terceira Idade. In: FLORENTINO, Adilson; TELLES, Narciso (org.). Cartografias do Teatro. Uberlândia: EDUFU, 2009. p. 133-143.

SCHNEIDER, Rodolfo Herberto; IRIGARAY, Tatiana Quarti. O envelhecimento na atualidade: aspectos cronológicos, biológicos, psicológicos e sociais. : aspectos cronológicos, biológicos, psicológicos e sociais. Estudos de Psicologia, Campinas, v. 4, n. 25, p. 585-593, dez. 2008.

TELLES, Narciso. Pedagogia do Teatro: práticas contemporâneas na sala de aula. Práticas contemporâneas na sala de aula. Campinas: Papirus, 2013. 